\title{
Eosinophil cationic protein and tidal flow volume loops in children $0-2$ years of age
}

\author{
K.C. Lødrup Carlsen*+, R. Halvorsen**, S. Ahlstedt ${ }^{++}, \mathrm{K}-\mathrm{H}$. Carlsen**
}

Eosinophil cationic protein and tidal flow volume loops in children 0-2 years of age. K.C. Lфdrup Carlsen, R. Halvorsen, S. Ahlstedt, K-H. Carlsen. (C)ERS Journals Ltd 1995. ABSTRACT: Many children with recurrent wheezing in early childhood develop asthma. Objective parameters to describe different groups of wheezers are limited, but tidal flow volume (TFV) response to inhaled salbutamol has demonstrated differences between children with and without asthma. Also, eosinophil cationic protein (ECP) has been associated with declining lung function in older children. We therefore investigated whether lung function and serum ECP (s-ECP) could differentiate between groups of wheezy young children.

TFV loops were measured in 79 awake children (mean age 14 months). Minimum two wheezy episodes (mean 3.2) or minimum 4 weeks persistent wheeze were reported in 41 children (cases), whereas the 38 controls had no history of wheeze. Airways responsiveness (change in ratio of time until peak expiratory flow to total expiratory time ( $t \mathrm{PEF} / \mathrm{t} \mathrm{E})$ after inhaled nebulized salbutamol) was measured in 26 cases and 24 controls. Serum ECP and serum myeloperoxidase (s-MPO) were measured in all children.

Cases had significantly lower mean $t \mathrm{PEF} / t \mathrm{E}(0.21)$ than controls $(0.33)$, and higher mean s-ECP $\left(21.9 \mu \mathrm{g} \cdot \mathrm{L}^{-1}\right)$ than controls $\left(14.0 \mu \mathrm{g} \cdot \mathrm{L}^{-1}\right)$. Serum ECP (but not $\mathrm{s}$-MPO) correlated significantly with the percentage change in $t \mathrm{PEF} / \mathrm{t} \mathrm{E}$ from baseline $(r=0.7)$, but not with initial $t$ PEF/tE. Serum ECP increased significantly with increasing immunoglobulin $\mathrm{E}$ (IgE), airways responsiveness and eosinophil count, but decreased with increasing age.

TFV responsiveness to salbutamol and s-ECP levels correlate strongly, both probably reflecting airways inflammation, and may possibly be valuable prognostic tools in recurrent wheezy infants and toddlers.

Eur Respir J., 1995, 8, 1148-1154.

\begin{abstract}
*Paediatric Dept, Ullevål Hospital, Oslo, Norway. ${ }^{+D e p t ~ o f ~ E p i d e m i o l o g y, ~ N a t i o n a l ~}$ Institute of Public Health, Oslo, Norway. **Voksentoppen Centre for children with asthma and allergy, Ullveien, Oslo, Norway.

${ }^{++}$Pharmacia Diagnostics, Uppsala, Sweden.
\end{abstract}

Correspondence: K.C. Lødrup Carlsen Paediatric Dept

Ullevål Hospital

N 0407 Oslo

Norway

Keywords: Airways reversibility child

eosinophil cationic protein

salbutamol

tidal flow volume loops

Received: November 211994

Accepted after revision March 281995

This study was supported by a grant from the National Research Council (Norway), and by Pharmacia Diagnostics, Uppsala, Sweden.
Wheezy illnesses in early childhood are common, but are not optimally defined and have different aetiologies and different outcome [1,2]. Although wheezy lower respiratory illnesses occur in $20-25 \%$ of children under 5 yrs of age, only a proportion of these will later be classified to suffer from bronchial asthma [1, 3]. Objective tools which could predict diagnosis and prognosis in the youngest age groups would, therefore, be helpful in making therapeutic decisions [4]. Measurements of bronchial reactivity for diagnosis and assessment of disease progress have not been generally available in paediatric pulmonary medicine for several reasons. Methods commonly used for lung function measurements in children less than 2 yrs of age have usually required natural sleep (neonates) or sedated sleep in the subjects, thus limiting the use of such measurements in routine clinical practice. Secondly, there is controversy about the role of airway reactivity during the first years of life, and the methods used for such evaluation $[1,5]$.

During the last few years, measurements of tidal breathing flow volume (TFV) loops have been increasingly employed in neonates and young children. As such measurements have been shown to be possible and relatively simple to perform in awake neonates and preschool children [6-9], this could become an important supplement to clinical evaluation and diagnosis of respiratory disease. Airways responsiveness to salbutamol, assessed by a significant change in the ratio of time until peak expiratory flow to total expiratory time $(t \mathrm{PEF} / t \mathrm{E})$ was demonstrated among asthmatic children without clinical signs of bronchopulmonary obstruction (BPO) at the time of testing, but not in the majority of controls without asthma [9]. This suggests the presence of labile airways in children with asthma in contrast to those without disease. It is now generally accepted, as already suggested by OSLER in 1892 [10], that asthma is an inflammatory disease of the lower airways [11]. Recently, increased serum levels of the eosinophil degranulation product, eosinophil cationic protein (ECP), have been found in subjects with asthma compared to nonatopic, nonasthmatic subjects $[12,13]$. This was taken as a sign of activation of eosinophils during the inflammatory process in the airways. In the quest for objective parameters of asthma in young children, measures of airways inflammation as well as measures of the resultant airways responsiveness should probably be included. Also, 
neutrophils releasing myeloperoxidase (MPO) upon activation have been proposed as part of the asthma inflammatory process, although to a limited extent [14]. The present study, therefore, aimed to investigate whether measurements of serum ECP (s-ECP) and s-myeloperoxidase (MPO) [15], together with lung function measurements by TFV loops, could yield diagnostic information not obtainable by standard clinical evaluation and medical history in wheezy children under 2 yrs of age.

\section{Subjects and methods}

\section{Design}

All subjects were enrolled within their first 4 days of life in a cohort established from January 1, 1992 to March 10, 1993, in the project "Environment and Childhood Asthma" in Oslo. From this cohort of approximately 3,800 children (which is presently under follow-up for the development of wheezy illness) cases and controls were defined. As definition of cases and controls is presently ongoing (at the time of manuscript preparation), the number of subjects in the present study is no reflection of frequency of BPO in the cohort. Inclusion criteria for cases were minimum two episodes of BPO or persistent BPO for at least 4 weeks. The subjects were included in the study as soon as possible after fulfilling the inclusion criteria.

Due to the large number of subjects in the cohort, verification of all episodes of BPO by a doctor was not possible. Thus, the definition of cases was based upon the verification by a doctor of at least one episode of BPO (as judged by the recorded clinical signs) and a medical history which was consistent (as judged by a diagnosis group of three senior paediatricians) with recurrent or persistent BPO.

The control subjects were selected from the cohort of "Environment and Childhood Asthma" on the basis of being the child born closest in time to the case, providing he/she had no medical history suggestive of BPO. However, as lung function measurements and blood sampling were not successfully performed in all children, an exact age-matching was not possible in the present study. The child with his/her parents was invited to attend the clinic for clinical examination, lung function measurements and blood tests. All these investigations were performed successively during the same visit, which took place at least 3 weeks after an acute exacerbation of lower respiratory illness. The children did not have symptoms of respiratory tract infection at the time of measurements.

\section{Subjects}

Seventy nine children (43 males and 36 females) with a mean age of 14 months (range 2-26 months) were included in the present study. The cases included had experienced a minimum of two episodes of BPO (35 children) or one BPO lasting at least 4 weeks (eight children) at the time of inclusion. Mean number of BPO episodes reported for the cases was 3.2 (95\% confidence
Table 1. - Demographic data of cases and controls

\begin{tabular}{lcc}
\hline & $\begin{array}{c}\text { Cases } \\
\mathrm{n}=47\end{array}$ & $\begin{array}{c}\text { Controls } \\
\mathrm{n}=38\end{array}$ \\
\hline Gender M/F & $24 / 17$ & $19 / 19$ \\
Age months & $12 \pm 6$ & $16 \pm 8$ \\
Family history of atopy* & & \\
$\quad$ None of the parents & 12 & 20 \\
One of the parents & 20 & 13 \\
Both parents & 9 & 4 \\
Any time eczema & 12 & 6 \\
\hline
\end{tabular}

*: atopy in this context comprises the atopic-related diseases asthma, eczema and rhinoconjunctivitis. Positive family history of atopic-related diseases is given for disease reported to have occurred in the parents at any time. "Any time eczema" represents the number of children with a strongly suggestive history of, or physician diagnosed, eczema at the time of investigation. Age is given as mean \pm SD. M: male; F: female.

interval 2.5-3.9). The controls had no history of BPO at the time of inclusion.

Demographic data for the two groups of subjects are given in table 1 . Twelve cases and six controls had either a history strongly suggestive of eczema or overt eczema at the time of testing. Regular or on-demand use of short-term acting $\beta_{2}$-agonists had been used for $1-40$ weeks (mean 5.4 weeks) by 35 cases $(85 \%)$. Eleven cases had used nebulized disodium cromoglycate for 230 weeks (mean 11 weeks), whereas nebulized budesonide had been used in four cases before inclusion for 1, 4, 4 and 16 weeks, respectively. No bronchodilating medication was given to the children prior to measurements on the day of testing. None of the children had received long-acting $\beta_{2}$-agonist, and theophyllines or antihistamines had not been given within the last $72 \mathrm{~h}$ prior to measurements.

\section{Lung function measurements}

Lung function was measured by tidal flow volume (TFV) loops, using the Sensormedics 2600. A tightfitting face-mask with an air inflated cuff (Vital Signs inc.) size 3 was connected to a triple screen $0-30 \mathrm{~L} \cdot \mathrm{min}^{-1}$ pneumotachograph (4500 series Hans Rudolph, Missouri, USA). Dead space of the pneumotachograph with the tube connections was approximately $5.5 \mathrm{~mL}$. Volume was derived by digital integration of the flow signal at a sampling frequency of 256 samples $\cdot \mathrm{s}^{-1}$.

Calibration of flow and volume signals was performed daily with a $100 \mathrm{~mL}$ precision syringe (Hans Rudolph, Missouri, USA). A secondary step in the calibration process provided for a correction for alinearity and asymmetry in the pneumotachograph, valve, tubing and transducer system with a 128 point linearization reference table [8].

The ratio of time until peak expiratory flow to total expiratory time $(t \mathrm{PEF} / t \mathrm{E}$ was calculated by separate measurements of time to peak expiratory flow and total expiratory time by the computer. The computer sorted through the flow and volume pairs in each curve to find the maximum flow and subsequently calculated the volume exhaled to the point of peak flow as a percentage of the total exhaled volume $V \mathrm{PEF} / V \mathrm{E})$. 
Representative curves were selected from a series of breaths during established tidal breathing based upon identifying loops with as stable volume and shape as possible, and the lowest possible respiratory rate. Four curves were stored initially with four subsequent breaths temporarily stored. The final four curves to be analysed were selected from these eight. The results are given as the mean of these four curves for each test.

The study was approved by the Regional Medical Ethics Committee.

\section{Inflammatory markers}

Blood was drawn within $1 \mathrm{~h}$ of lung function measurements (between 10 a.m. and 2.15 p.m.) into SST vacutainer tubes, and allowed to clot at stable room temperature for $1 \mathrm{~h}$ before centrifugation for ECP and MPO assays. The pipetted serum was stored at $-70^{\circ} \mathrm{C}$. All handling of the blood tests were performed by one nurse using a standardized procedure, and no diurnal variation should affect the results with such timing of the sampling [16].

Serum ECP was measured [17] by the Pharmacia CAP system ECP fluoro enzyme immunoassay (FEIA) method, according to the instructions of the manufacturer. Briefly, monoclonal anti-ECP antibodies covalently coupled to immunoCAP (Pharmacia) were allowed to react with patient serum samples and subsequently, after washing, with monoclonal anti-ECP antibodies containing fluorogenic labelling. The level of fluorescence after adding fluorogenic substrate was measured by a Fluorocount 96 (Pharmacia). The measuring range was 2-200 $\mu \mathrm{g} \cdot \mathrm{L}^{-1}$ in undiluted serum. The cross-reactivity with other proteins from granulocytes is less than $0.1 \%$ according to the specifications of the manufacturer.

Serum MPO was measured [18] by the Pharmacia MPO radioimmunoassay, according to the instructions of the manufacturers. Briefly, diluted patient serum and ${ }^{125} \mathrm{I}-$ MPO was incubated with polyclonal anti-MPO antibodies on sepharose. After adding decanting suspension, incubation and decanting, radioactivity was measured in a gamma-counter and concentrations determined by comparison to a standard curve. The cross-reactivity with other granular proteins is less than $0.1 \%$, according to the specifications of the manufacturer.

\section{Statistical analysis}

Nonparametric analyses were employed for comparisons between the groups. Categorical variables between groups were analysed by Chi-square tests. All tests were performed with two tails. Simple bivariate correlation analysis (Pearsons correlation coefficient) were performed between inflammatory marker levels and lung function measurements and the use of inhaled medication. Multiple regression analysis was performed to evaluate the influence upon inflammatory marker levels by several different variables. Results are given as mean values with $95 \%$ confidence interval $(95 \% \mathrm{CI})$ in parentheses, unless otherwise stated. Immunoglobulin E (IgE) results are given as geometric mean and 95\% CI for geo- metric means. Differences were regarded as significant with p-values at or below 5\%. Subjects were defined as responders, nonresponders or paradoxical responders depending upon the magnitude of change in $t \mathrm{PEF} / \mathrm{t}$ from before to after inhalation $(\Delta t \mathrm{PEF} / \mathrm{t} \mathrm{E})$ of salbutamol.

Responder $=\Delta t \mathrm{PEF} / t \mathrm{E}$ improved $\geq 2 \mathrm{SD}$ of the intrasubject variation in $t \mathrm{PEF} / t \mathrm{E}$; nonresponder $=\Delta t \mathrm{PEF} / t \mathrm{E}<2 \mathrm{SD}$ of the intrasubject variation in $t \mathrm{PEF} / \mathrm{tE}$; paradoxical responder $=\Delta t \mathrm{PEF} / t \mathrm{E}$ declined $\geq 2 \mathrm{SD}$ of the intrasubject variation in $t \mathrm{PEF} / t \mathrm{E}$. Statistical Package for Social Sciences (SPSS) for Windows were used for statistical analysis.

\section{Results}

The results of TFV measurements, s-ECP, s-IgE and eosinophil count are given for cases and controls in table 2 .

\section{Lung function}

Among cases, mean time and volume ratios $t \mathrm{PEF} / t \mathrm{E}$ $(0.22)$ and $V \mathrm{PEF} / V_{\mathrm{E}}(0.27)$ were significantly lower than among controls $(0.33$ and 0.37 , respectively) $(\mathrm{p}<0.001)$ before inhalation of salbutamol (table 2), but not after inhalation (fig. 1).

Comparison of the response to salbutamol demonstrated a significantly larger mean $\Delta t \mathrm{PEF} / t \mathrm{E}$ among the cases $(0.09)$ than controls $(-0.01)(\mathrm{p}<0.005)$, as was also seen for $\Delta V_{\mathrm{PEF}} / V_{\mathrm{E}}(0.11$ and 0.01 , respectively $)(\mathrm{p}<0.005)$ (table 2). Among the 26 cases with reversibility test, 13 were classified as responders to salbutamol versus two of the 24 controls. Eleven cases and 18 controls were classified as nonresponders, whereas two cases and four controls were classified as having paradoxical response to salbutamol, the distribution being significantly different between cases and controls $(\mathrm{p}<0.01)$.

Table 2. - Tidal time and volume ratios, airway inflammation markers and s-IgE levels in children 0-2 yrs of age

\begin{tabular}{lcc}
\hline & \multicolumn{1}{c}{ Cases } & \multicolumn{1}{c}{ Controls } \\
\hline$t \mathrm{PEF} / t \mathrm{E}$ & $0.22(0.18-0.25)$ & $0.33(0.29-0.36)^{\#}$ \\
$V \mathrm{PEF} / V \mathrm{E}$ & $0.27(0.23-0.30)$ & $0.37(0.34-0.41)^{\#}$ \\
$\Delta t \mathrm{PEF} / t \mathrm{E}$ & $0.09(0.04-0.14)$ & $-0.01(-0.05-0.02)^{* * *}$ \\
$\Delta V \mathrm{PEF} / V \mathrm{E}$ & $0.11(0.06-0.16)$ & $0.01(-0.4-0.05)^{* * *}$ \\
$\mathrm{~s}-\mathrm{ECP} \mu \mathrm{g} \cdot \mathrm{L}^{-1}$ & $21.9(15.6-28.1)$ & $14.0(8.2-19.7)^{* *}$ \\
$\mathrm{IgE} \mathrm{kU} \cdot \mathrm{L}^{-1}$ & $13.7(9.0-20.9)$ & $10.2(5.7-17.8)$ \\
Eosinophil count & $0.32(0.23-0.41)$ & $0.21(0.16-0.27)^{*}$ \\
$\quad 10^{9} \cdot \mathrm{L}^{-1}$ & & \\
\hline
\end{tabular}

Results are given as mean values and $95 \%$ confidence interval in parenthesis, except the IgE levels, which are given as geometric mean and 95\% confidence interval of geometric mean in parenthesis. $t \mathrm{PEF} / t \mathrm{E}$ and $V \mathrm{PEF} / V \mathrm{E}$ are baseline values. $t \mathrm{PEF} / t \mathrm{E}$ : ratio of time until peak expiratory flow to total expiratory time; $V \mathrm{PEF} / V_{\mathrm{E}}$ : volume exhaled to the point of peak expiratory flow as a percentage of the total exhaled volume. $\Delta t$ $\mathrm{PEF} / t \mathrm{E}: t \mathrm{PEF} / t \mathrm{E}$ after inhaled salbutamol minus baseline $t \mathrm{PEF} / t \mathrm{E}$; $\Delta V_{\mathrm{PEF}} / V_{\mathrm{E}}: V_{\mathrm{PEF}} / V_{\mathrm{E}}$ after inhaled salbutamol minus baseline

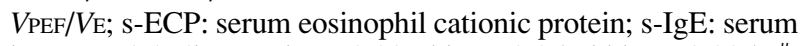
immunoglobulin E. *: $\mathrm{p}=0.02 ; * *: \mathrm{p}<0.05 ; * * *: \mathrm{p}<0.005$; \#: $\mathrm{p}<0.001$. 


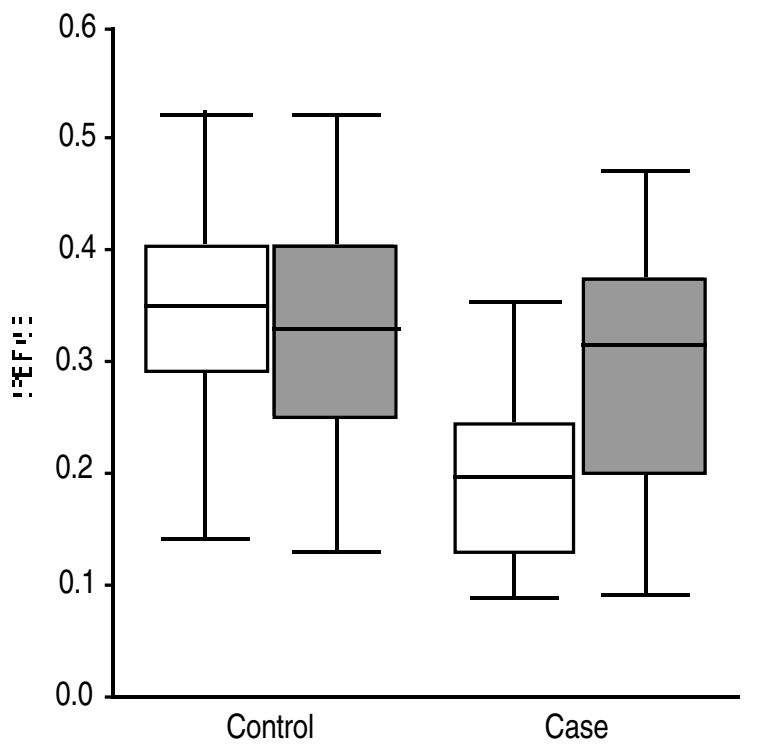

Fig. 1. - Box-whiskers plot of $t$ PEF/tE before $(\square)$ and after ( $\square$ ) inhalation of salbutamol in cases and controls. The ratio of time until peak expiratory flow to total expiratory time $(t \mathrm{PEF} / t \mathrm{E})$ was significantly lower among cases before $(\mathrm{p}<0.001)$, but not after inhalation of salbutamol. Boxes represent the 25 th and 75 th percentiles with median value (50th percentile) in the centre. The whiskers represent the range.

The 15 cases who used anti-inflammatory treatment (disodium cromoglycate or budesonide) had significantly lower mean $t \mathrm{PEF} / t \mathrm{E}(0.16,95 \%$ CI $0.13-0.19)$ than the other cases $(0.24,95 \%$ CI $0.20-0.29)$. Furthermore, although not significant, the response to salbutamol given as percentage change in TFV loops from baseline expressed as:

$$
\frac{(t \mathrm{PEF} / t \mathrm{E} \text { after }-t \mathrm{PEF} / t \mathrm{E} \text { before }) \text { inhalation }}{t \mathrm{PEF} / t \mathrm{E} \text { before inhalation }} \times 100
$$

was higher among the cases who used anti-inflammatory treatment $(n=9)(73 \%, 95 \%$ CI 32.5-112.8\%) compared to the other cases $(n=17)(55 \%, 95 \%$ CI $10.1-99.6 \%)$. No significant differences in lung function measurements were found among the eight children with chronic wheeze compared to children with recurrent wheeze.

Mean respiratory rate (breaths $\cdot \mathrm{min}^{-1}$ ) was significantly higher in cases $(45,95 \%$ CI $41-49)$ than controls $(39$, $95 \%$ CI 35-43) both before $(\mathrm{p}<0.005)$ and after $(\mathrm{p}=0.01)$ inhalation of salbutamol, but mean respiratory rate did not differ in either group from before to after inhalation. No significant differences related to gender were found for tidal volume, respiratory rate or the ratios $t \mathrm{PEF} / t \mathrm{E}$ and $V \mathrm{PEF} / V_{\mathrm{E}}$ in either group.

\section{$s-E C P$ and $M P O$}

Mean s-ECP level was significantly higher in the cases than in the controls $(\mathrm{p}<0.05)$ (fig. 2$)$, as was mean serum eosinophil count (table 2) $(\mathrm{p}=0.02)$. No significant difference in s-ECP level was found between children with chronic wheeze compared to those with recurrent wheeze.

Children with $(n=18)$ and without a history of eczema $(n=61)$ did not have significantly different s-ECP levels

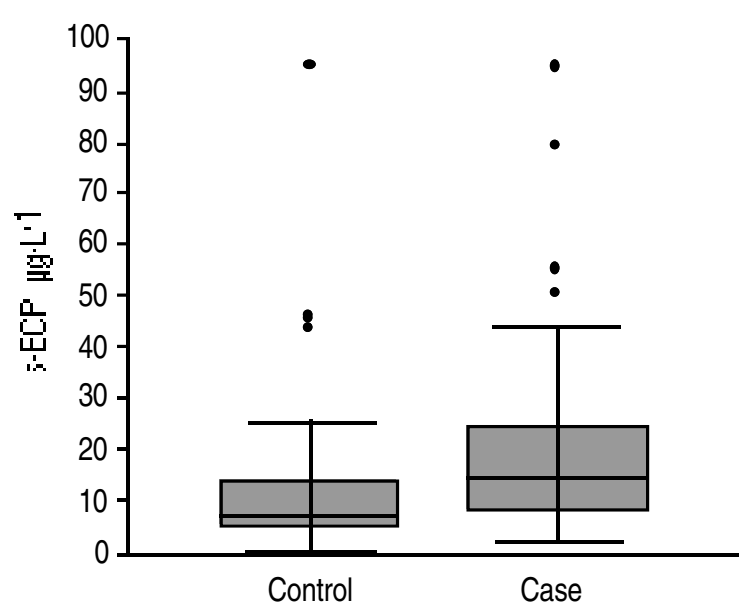

Fig. 2. - Box-whiskers plot of serum eosinophilic cationic protein (s-ECP) in cases and controls. Serum ECP was significantly lower among controls than cases $(\mathrm{p}<0.05)$. Boxes represent the 25 th and 75 th percentiles with median value (50th percentile) in the centre. The whiskers represent the range except for the outliers (dots) in both groups located more than 1.5 times the box size from the box.

(12.9, 95\% CI 9.4-16.4; and 20.1, 95\% CI 14.5-25.6, respectively). Serum ECP levels did not differ significantly between those with no, one or two parents with reported atopic disease. No significant differences in $\mathrm{s}$-IgE levels were found between those with and without eczema. Eosinophil count correlated significantly with $\mathrm{s}-\mathrm{ECP}(\mathrm{r}=0.57 ; \mathrm{p}<0.001)$. A weak $(\mathrm{r}=-0.38 ; \mathrm{p}=0.001)$ negative correlation was found between age and s-ECP levels for all children, as well as for the controls alone. No significant correlation was found between s-ECP and s-IgE.

The four children treated with budesonide had a mean s-ECP of $19.8 \mu \mathrm{g} \cdot \mathrm{L}^{-1}$ (range $8.6-43.7 \mu \mathrm{g} \cdot \mathrm{L}^{-1}$ ) whereas the 11 children treated with disodium cromoglycate had slightly higher s-ECP levels of $22.2 \mu \mathrm{g} \cdot \mathrm{L}^{-1}$ (range 4-94.5 $\left.\mu \mathrm{g} \cdot \mathrm{mL}^{-1}\right)$. No analyses for significance of differences were performed due to the low number in each group.

Mean s-MPO was higher among cases $\left(729 \mu \mathrm{g} \cdot \mathrm{L}^{-1}\right.$; 95\% CI 558-899) than controls $\left(589 \mu \mathrm{g} \cdot \mathrm{L}^{-1} ; 95 \% \mathrm{CI}\right.$ 469-709), but the difference was not statistically significant.

\section{Inflammatory markers and lung function}

A significant correlation was found between s-ECP and percentage change in $t \mathrm{PEF} / t \mathrm{E}$ from baseline $(\mathrm{r}=0.70)$, $(\mathrm{p}<0.001)$ (fig. 3). The correlation improved to 0.76 $(\mathrm{p}<0.001)$ by excluding children with eczema, although in children with eczema the correlation between s-ECP and percentage change in $t \mathrm{PEF} / \mathrm{t} \mathrm{E}$ was the same as for the total group of children $(r=0.70)$. Eosinophil count did not show a significant correlation with $\Delta t \mathrm{PEF} / \mathrm{t} \mathrm{E}$, and only a weak correlation to the percentage change in $t \mathrm{PEF} / \mathrm{t}$ from baseline $(\mathrm{r}=0.38 ; \mathrm{p}=0.01)$. No correlation was found between baseline $t \mathrm{PEF} / t \mathrm{E}$ and s-ECP or s-MPO levels, nor was there any correlation between s-MPO levels and $\Delta t \mathrm{PEF} / \mathrm{tE}$. Furthermore, using the percentage change in $t \mathrm{PEF} / t \mathrm{E}$ from baseline as the dependent variable, no significant multiple regression model could be 


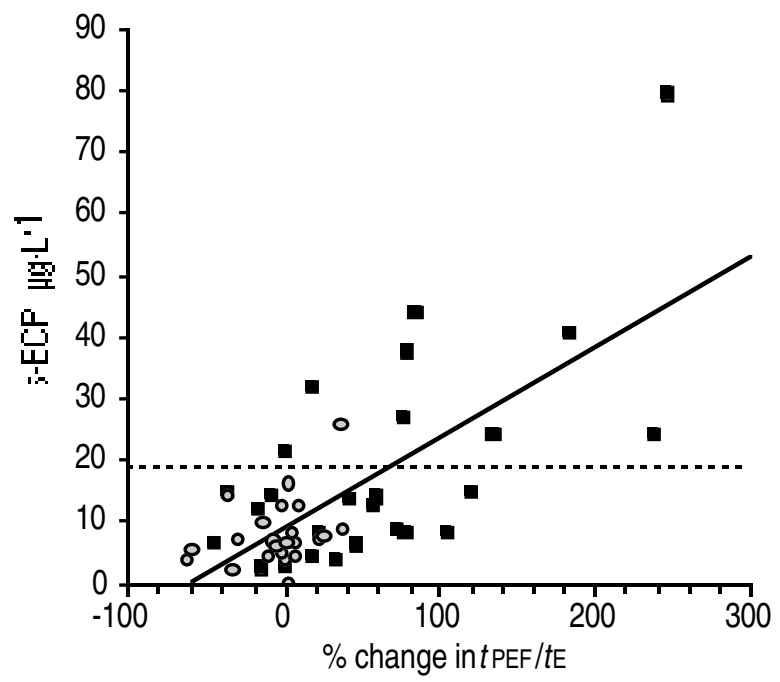

Fig. 3. - Regression of response to salbutamol $(\Delta t \mathrm{PEF} / \mathrm{tE} \%)$ on serum eosinophil cationic protein (s-ECP) levels. The response to salbutamol is given as: ( $t \mathrm{PEF} / t \mathrm{E}$ after $-t \mathrm{PEF} / t \mathrm{E}$ before) inhalation $\times 100$ ( $\mathrm{x}$ axis) $t \mathrm{PEF} / \mathrm{t} \mathrm{E}$ before inhalation

The regression was significant $(\mathrm{r}=0.70 ; \mathrm{p}<0.001)$ for the 26 cases and 24 controls. Regression line is given for all subjects. The reference line (dashed line) is the upper $95 \%$ confidence limit of s-ECP levels among the controls $\left(19.7 \mu \mathrm{g} \cdot \mathrm{L}^{-1}\right)$. $t \mathrm{PEF} / \mathrm{tE}$ : ratio of time to peak expiratory flow to total expiratory time. $\mathbf{n}$ : case; $\bigcirc$ : control.

Table 3. - Lung function and serum MPO, eosinophil and IgE levels in children with serum ECP above and within "reference range"

\begin{tabular}{|c|c|c|}
\hline & $\begin{array}{c}\text { s-ECP } \\
<19.7 \mu \mathrm{g} \cdot \mathrm{L}^{-1}\end{array}$ & $\begin{array}{c}\text { s-ECP } \\
>19.7 \mu \mathrm{g} \cdot \mathrm{L}^{-1}\end{array}$ \\
\hline $\mathrm{n}$ & 57 & 22 \\
\hline$f_{\mathrm{R}}$ breaths $\cdot \mathrm{min}^{-1}$ & $40(37-44)$ & $47(42-51)^{*}$ \\
\hline$\Delta t \mathrm{PEF} / t \mathrm{E}$ & $0.00(-0.3-0.03)$ & $0.17(0.10-0.25)^{* *}$ \\
\hline$\Delta V \mathrm{PEF} / V_{\mathrm{E}}$ & $0.02(-0.01-0.06)$ & $0.19(0.11-0.27)^{* *}$ \\
\hline $\mathrm{s}-\mathrm{MPO} \mu \mathrm{g} \cdot \mathrm{L}^{-1}$ & $502(435-569)$ & $1076(800-1352)^{* *}$ \\
\hline Eosinophils $10^{9} \cdot \mathrm{L}^{-1}$ & $0.21(0.17-0.26)$ & $0.46(0.32-0.56)^{* *}$ \\
\hline $\mathrm{s}-\operatorname{IgE} \mathrm{kU} \cdot \mathrm{L}^{-1}$ & $18.7(10.5-26.8)$ & $51.3(-2.3-104.8)$ \\
\hline \multicolumn{3}{|l|}{ Familial atopy ${ }^{\dagger}$} \\
\hline One parent & 24 & 9 \\
\hline Both parents & 9 & 4 \\
\hline
\end{tabular}

Results are given as mean values and $95 \%$ confidence intervals in parenthesis. "Reference range" is defined as s-ECP below the upper 95\% confidence limit for s-ECP among controls $\left(19.7 \mu \mathrm{g} \cdot \mathrm{L}^{-1}\right)$. Seven controls and 15 cases had s-ECP values above the upper reference limit. $f_{\mathrm{R}}$ : respiratory frequency; s-MPO: serum myeloperoxidase. ${ }^{\dagger}:$ Family history. For further abbreviations see legend to table 2. Family history of atopy indicates the presence of atopic-related disease in one or both parents. *: $\mathrm{p}<0.01 ; * * \mathrm{p}<0.001$. defined for s-IgE, age and eosinophil count alone. However, including s-ECP as an independent variable gave a significant regression with $\mathrm{r}^{2}=0.45(\mathrm{p}<0.001)$.

Using a linear regression on s-ECP, including the percentage change in $t \mathrm{PEF} / \mathrm{t}$ from baseline, IgE levels and age, $67 \%$ of the variability in s-ECP was explained $\left(r^{2}=0.67\right)$, increasing to $73 \%$ by adding eosinophil count into the equation. The effect of age on s-ECP was -0.4 $\mu \mathrm{g} \cdot \mathrm{L}^{-1}$ per month increase. Using eosinophil count as dependent variable in the regression model, percentage change in $t \mathrm{PEF} / t \mathrm{E}$ from baseline, IgE levels and age could only explain $26 \%$ of the variability.

\section{$s-E C P$ and "reference range"}

A cut-off point for "reference range" was arbitrarily chosen as the upper $95 \%$ confidence limit for s-ECP $\left(=19.7 \mu \mathrm{g} \cdot \mathrm{L}^{-1}\right)$ among the controls, resulting in 57 children with s-ECP within, and 22 children with s-ECP levels above the "reference range". Lung function values and s-MPO levels, eosinophil count and IgE levels for subjects with values within compared to above "reference range" are given in table 3 . Initial $t \mathrm{PEF} / t \mathrm{E}$ did not differ significantly between these groups, but the response to salbutamol $(\Delta t \mathrm{PEF} / \mathrm{t} \mathrm{E})$ was significantly larger among those with high s-ECP (mean 0.17) compared to those within "reference range" (mean 0.004) $(\mathrm{p}<0.001)$ (table 3). Characteristics of the four controls shown as "outliers" among the controls in figure 2 are shown in table 4. None of them had eczema or history of parental atopic related disease. Unfortunately, only baseline and not reversibility measurements of lung function were obtained in these infants.

Five children with s-ECP above "reference range" (4 males and female) had eczema (all cases), and any time parental atopy (asthma, rhinoconjunctivitis or eczema) was reported for both parents in two children and for one parent for one child.

\section{Discussion}

Serum ECP, but not s-MPO levels were significantly higher in children 0-2 yrs of age with recurrent wheeze than in controls. Airways response to salbutamol measured by TFV loops correlated significantly with s-ECP levels, and $74 \%$ of the variation in s-ECP levels was explained by the magnitude of airways reactivity, IgE level, eosinophil count and age. No significant relationship was found between s-MPO and lung function measurements.

The results in the present study of baseline, but not post-salbutamol, tidal time and volume ratios being lower

Table 4. - Characteristic of the four controls with highest s-ECP levels

\begin{tabular}{|c|c|c|c|c|c|}
\hline $\begin{array}{l}\text { Child } \\
\text { No. }\end{array}$ & $\begin{array}{l}\mathrm{s}-\mathrm{ECP} \\
\mu \mathrm{g} \cdot \mathrm{L}^{-1}\end{array}$ & $\begin{array}{l}\mathrm{s}-\mathrm{MPO} \\
\mu \mathrm{g} \cdot \mathrm{L}^{-1}\end{array}$ & $\begin{array}{c}\text { Eosinophils } \\
10^{9} \cdot \mathrm{L}^{-1}\end{array}$ & $\begin{array}{c}\mathrm{s}-\mathrm{IgE} \\
\mathrm{kU} \cdot \mathrm{L}^{-1}\end{array}$ & $t \mathrm{PEF} / t \mathrm{E}$ \\
\hline 1 & 95.8 & 1200 & 0.6 & 2.5 & 0.20 \\
\hline 2 & 45.4 & 900 & 0.4 & 44 & 0.14 \\
\hline 2 & 44.8 & 1000 & Missing & 126 & 0.15 \\
\hline 4 & 43.6 & 1890 & 0.2 & $<2.0$ & 0.32 \\
\hline
\end{tabular}

For abbreviations see legends to tables 2 and 3 . 
in subjects with recurrent wheeze compared to the controls are similar to the results found in a previous study in preschool children with and without asthma [9], and in chronic adult asthmatic versus nonasthmatic cases [19]. The mean $t \mathrm{PEF} / \mathrm{tE}$ in the present study in the asthma group (0.21) was slightly lower than that reported by MARTINEZ et al. [20] in the group of (sedated) infants who subsequently developed wheezing (0.24), but higher than the baseline values in our previous study of asthmatic preschool children (0.16). However, $t \mathrm{PEF} / t \mathrm{E}$ may be lower among infants and young children after developing recurrent wheeze than before any symptoms have occurred.

The change in response to salbutamol was also similar to that seen in our previous study [9], and is supported by the findings of LONKY and TISI [21], who found reversibility of airways' obstruction after inhaled isoproterenol in adults by TFV loops. However, the recurrent wheezers in the present study did not have any clinically detectable BPO during testing, and we therefore consider that this improvement may be a consequence of the reactivity in the airways. In support of this, KRAEMER and ScHÖNI [22] demonstrated reversibility to bronchodilators in infants and preschool children with asthma or in the reconvalescence after bronchiolitis by other lung function methods, such as body plethysmography.

The difference between cases and controls in respiratory rates both initially and after inhalation of salbutamol probably does not influence these results, as no significant correlation between respiratory rate and time and volume ratios was found. Also, respiratory rates were stable in the two groups despite improved time and volume ratios after inhalation among the cases only.

The present study demonstrated higher s-ECP in recurrent wheezers than controls. Other studies in older subjects have demonstrated increased s-ECP in asthmatic patients compared to those without asthma $[12,13,23$, 24]. Several studies have demonstrated higher s-ECP levels in atopic compared to nonatopic subjects [13, 25]. The presence or absence of atopy is not yet known in our subjects due to their young age. However, the higher levels of s-IgE as well as eosinophil count among our subjects with the highest s-ECP are suggestive of a risk of developing atopy. However, no differences were found in s-ECP levels related to parental atopic history in the present study.

Few studies of s-ECP in this age group with obstructive airways disease have been published. However, one study, to support our findings of increased s-ECP levels in children with a history of wheeze, demonstrated increasing levels of s-ECP during the reconvalescent period after acute bronchiolitis in infants [25]. They also found higher s-ECP levels in infants with acute bronchiolitis than infants without a history of wheeze. However, direct comparison between the studies must be made with caution, as our cases had all experienced recurrent wheeze, but were not wheezing at the time of investigation.

The age effect upon s-ECP, although significant, was only in the order of an increase in s-ECP of $0.4 \mu \mathrm{g} \cdot \mathrm{L}^{-1}$ per one month decrease in age. Thus, age is unlikely to explain the difference in s-ECP levels between cases and controls, as the difference in mean age was approximately 3.5 months, whereas the difference between cases and controls in mean s-ECP was $7.9 \mu \mathrm{g} \cdot \mathrm{L}^{-1}$. So far, no "reference range" of s-ECP for this age group has been defined. The manufacturer operates with an upper reference limit of $16 \mu \mathrm{g} \cdot \mathrm{L}^{-1}$, but this range has not been specified for very young children. In order to investigate possible characteristics of subjects with high s-ECP levels, an upper limit of "normal" s-ECP values would be valuable as a cut-off value. As s-ECP showed some inverse relationship to age in the present study, it seems reasonable to define a "reference range" for subjects 2 yrs of age and younger. We therefore chose the upper $95 \%$ confidence limit among children with no history of recurrent wheeze as the upper limit of the "reference range".

We found no significant correlation between s-MPO and lung function, nor could we demonstrate any significant difference in s-MPO between cases and controls. However, the significantly higher s-ECP but not s-MPO levels among cases compared to controls may suggest an increase in eosinophil activation rather than activation of neutrophils in the cases. The present study demonstrated a strong relationship between s-ECP and lung function only when the individuals' responses to salbutamol were assessed by $\Delta t \mathrm{PEF} / t \mathrm{E}$ and $\Delta V \mathrm{PEF} / V \mathrm{E}$, and not with baseline measurements alone. Our findings of a significant association between lung function and s-ECP are supported by some studies $[12,26]$, whereas others have failed to observe this [27, 28]. However, VIRCHOw et al. [29] did find a significant correlation between changes in forced expiratory volume in one second (FEV1) to albuterol and sputum ECP levels in adults with chronic obstructive airways disease. It should be noted, however, that in most other studies inhaled steroids have been used by most patients, making comparison to our findings difficult, as it has been shown in children $[12,25,27,28]$ that steroid treatment decreases s-ECP levels and airways responsiveness. The lack of correlation between s-ECP and baseline lung function in the present study, as also found by JUTUNEN-BACKMAN et al. [30] in older children with asthma, suggests that one single measurement of lung function is less sensitive to detect inflammatory activity than airways responsiveness assessed by repeated measurements. This hypothesis is supported by the strong correlation between the change in TFV loops from before to after inhalation and s-ECP levels in the present study.

Separating the subjects by the level of s-ECP, it was found that children with s-ECP levels above the presumed normal range $\left(19.7 \mu \mathrm{g} \cdot \mathrm{L}^{-1}\right)$ had the greatest changes in lung function after salbutamol inhalation, as well as increased IgE and eosinophil counts compared to children with s-ECP below $19.7 \mu \mathrm{g} \cdot \mathrm{L}^{-1}$ (table 3 ).

Serum levels of eosinophils and IgE did not relate to airways responsiveness to the same extent as s-ECP did. This indicates that s-ECP, a degranulation product of the preactivated eosinophils [28], is a more sensitive indicator of airways inflammation than eosinophils and sIgE levels.

The present study has demonstrated that tidal breathing 
lung function indices are sensitive indicators of airways lability as assessed by the response to salbutamol, and that increased response to salbutamol correlates strongly with increased levels of the airway inflammatory marker s-ECP. Although the present study did not investigate characteristics specific of asthmatic versus nonasthmatic subjects, our findings may possibly be important for prediction of asthma development in young wheezy children, considering the growing evidence of a role of eosinophils in the airway inflammatory processes in asthma $[13,26]$. Furthermore, the variability in s-ECP in our study suggests that there is a subgroup of wheezy infants and toddlers differing in airways responsiveness, IgE levels and eosinophil levels from other wheezy infants. It is, therefore, possible that the combined measurements of response to salbutamol as assessed by TFV-loops and serum levels of ECP, eosinophils and IgE, may indicate a group of infants who may benefit from different medical treatment than the remainder of recurrently wheezing infants and toddlers during the first few years of life. Further follow-up studies of the present cohort may hopefully give an answer to this question.

Acknowledgements: The authors are grateful to nurse M. Bru for her invaluable technical assistance with the study.

\section{References}

1. Silverman M. Out of the mouths of babes and sucklings: lessons from early childhood asthma. Thorax 1993; 48: 1200-1204.

2. Wilson NM. Wheezy bronchitis revisited. Arch Dis Child 1989; 64: 1194-1199.

3. Morgan WJ, Martinez FD. Risk factors for developing wheezing and asthma in childhood. Pediatr Clin North Am 1992; 39(6): 1185-1202.

4. Zach MS. To understand how babies breathe. Eur Respir $J$ 1993; 6: 158-159.

5. Le Souëf PN. Validity of methods used to test airway responsiveness in children. Lancet 1992; 339: 1282-1284.

6. Lødrup KC, Mowinckel P, Carlsen KH. Lung function measurements in awake compared to sleeping newborn infants. Pediatr Pulmonol 1992; 12: 99-104.

7. Lødrup Carlsen KC, Carlsen KH. Lung function in awake healthy infants the first five days of life. Eur Respir J 1993; 6: 1496-1500.

8. Lødrup Carlsen KC, Magnus P, Carlsen K-H. Lung function by tidal breathing in awake healthy newborn infants. Eur Respir J 1994; 7: 1660-1668.

9. Carlsen K-H, Lødrup Carlsen KC. Tidal breathing analysis in awake young children with and without asthma, and their response to salbutamol. Eur Respir J 1994; 7: 2154-2159.

10. Osler W. The principles and practice of medicine. New York, D. Appleton and Co., 1892.

11. International Consensus Report on Diagnosis and Treatment of Asthma. Eur Respir J 1992; 5: 601-641.

12. Zimmerman B, Lanner A, Enander I, Zimmerman RS, Peterson CG, Ahlstedt S. Total blood eosinophils, serum eosinophil cationic protein and eosinophil protein-X in childhood asthma: relation to disease status and therapy. Clin Exp Allergy 1993; 23: 564-570.

13. Sugai T, Sakiyama Y, Matumoto S. Eosinophil cationic protein in peripheral blood of pediatric patients with allergic disease. Clin Exp Allergy 1992; 22: 275-281.

14. Lacoste JY, Bousquet J, Chanez P, et al. Eosinophilic and neutrophilic inflammation in asthma, chronic bronchitis and chronic obstructive pulmonary disease. $J$ Allergy Clin Immunol 1993; 92: 537-548.

15. Venge P. Soluble markers of allergic inflammation. Allergy 1994; 49: 1-8.

16. Dahl R, Venge P, Olsson J. Blood eosinophil leukocytes and eosinophilic cationic protein: diurnal variation in normal subjects and in patients with bronchial asthma. Scand J Respir Dis 1978; 59: 323-325.

17. Peterson CGB, Enander J, Nyshand J, Andersson AS, Nilsson L Venge P. Radioimmunoassay of eosinophil cationic protein (ECP) by an improved method: establishment of normal levels in serum and turnover in vivo. Clin Exp Allergy 1991; 21: 561-567.

18. Bousquet J, Chanez P, Lacoste JY, et al. Indirect evidence of bronchial inflammation assessed by titration of inflammatory mediators in BAL fluid in patients with asthma. J Allergy Clin Immunol 1991; 88: 649-660.

19. Morris MJ, Lane DJ. Tidal expiratory flow patterns in airflow obstruction. Thorax 1981; 36: 135-142.

20. Martinez FD, Morgan WJ, Wright AL, Holberg CJ, Taussig LM, GMHA. Personnel. Diminished lung function as a predisposing factor for wheezing respiratory illness in infants. N Engl J Med 1988; 319: 1112-1117.

21. Lonky SA, Tisi GM. Determining changes in airway caliber in asthma: the role of submaximal expiratory flow rates. Chest 1980; 77: 741-748.

22. Kraemer R, Schöni MH. Improvement from pulmonary hyperinflation and bronchial obstruction following sympathomimetics systemically given in infants with bronchopulmonary disease. Z Erkrank Atmorg 1990; 174: 85-96.

23. Griffin E, Håkansson L, Formgren H, Jørgensen K, Peterson C, Venge P. Blood eosinophil number and activity in relation to lung function in asthmatic patients with eosinophilia. J Allergy Clin Immunol 1991; 87: 548-557.

24. Zimmerman B, Enander I, Zimmerman R, Ahlstedt S. Asthma in children less than 5 years of age: eosinophils and serum levels of the eosinophil proteins ECP and EPX in relation to atopy and symptoms. Clin Exp Allergy 1994; 24: 149-155.

25. Colocho Zelaya EA, Örvell C, Strannegård Ö. Eosinophil cationic protein in nasopharyngeal secretions and serum of infants infected with respiratory syncytial virus. Pediatr Allergy Immunol 1994; 5: 100-106.

26. Hedlin G, Ahlstedt S, Enander I, Håkansson L, Venge P. Eosinophil cationic protein (ECP), eosinophil chemotactic activity (ECA), neutrophil chemotactic activity (NCA) and tryptase in serum before and during bronchial challenge in cat-allergic children with asthma. Pediatr Allergy Immunol 1992; 3: 144-149.

27. Zimmerman B. Clinical experience with the measurement of ECP: usefulness in the management of children with asthma. Clin Exp Allergy 1993; 23S: 8-12.

28. Venge P. Serum measurements of eosinophil cationic protein (ECP) in bronchial asthma. Clin Exp Allergy 1993; 23: 3-7.

29. Virchow JC, Holsher U, Virchow C. Sputum ECP levels correlate with parameters of airflow obstruction. Am Rev Respir Dis 1992; 146: 604-606.

30. Jutunen-Backman K, Jarvinen P, Sorva R. Serum eosinophil cationic protein during treatment of asthma in children. J Allergy Clin Immunol 1993; 92: 34-48. 